THE INDUSTRIAL INSTITUTE FOR ECONOMIC AND SOCIAL RESEARCH

WORKING PAPER No. 451, 1996

PRICE DYNAMICS AND PRODUCTION LAGS

BY ASSAR LINDBECK AND DENNIS J. SNOWER 


\title{
PRICE DYNAMICS AND PRODUCTION LAGS
}

\author{
by Assar Lindbeck and Dennis J. Snower
}

\begin{abstract}
The paper shows how prolonged price inertia can arise in a macroeconomic system in which there are temporary price rigidities as well as production lags in the use of intermediate goods. In this context, changes in production demand - generated, say, by changes in the money supply - have long-lasting price and quantity effects. Specifically, a temporary demand shift generates "persistence" in price-quantity decisions, in the sense that the price-quantity effects of this shift persist for long after the shift has disappeared. A permanent demand shift generates "sluggishness" in price-quantity decisions, in the sense that the full price effects of the shift take a long time to appear and that meanwhile quantity effects are present.

JEL classification: D1, D43, D57, E12, E31, E32

Keywords: Price-rigidities, price inertia, production lags, New Keynesian economics

Assar Lindbeck

Institute for International Economic Studies and Institute for Industrial and Social Stockholm University Research

S-106 91 Stockholm Box 5501

Sweden S-11485 Stockholm, Sweden

Tel: (46) 8163078 Tel: (46) 87838458

Dennis J. Snower

Department of Economics

Birkbeck college

University of London

7, Gresse Street

London W1 1PA, U.K.
\end{abstract}





\section{PRICE DYNAMICS AND PRODLCTION LAGS}

\section{Introduction}

In this paper we develop a theory of price dynamics in which production lags in the use of intermediate inputs play a central role in determining how prices change through time. We thereby provide an explanation for price inertia that is observationally distinct from the ones given by the menu-cost and wage-price staggering theories, and which consequently generates distinctive predictions of how product demand changes affect both output and prices through time.

To do this in a particularly simple way, we consider an economy in which labor is used to produce intermediate goods, which in turn are used to produce final goods. The production process for the final goods involves a lag. The prices of the final goods are set before final demand is observed, i.e. they are precommitted before sales take place. The final good price level affects nominal wages, which in turn affect the intermediate good price (since labor produces the intermediate goods). Furthermore. the intermediate good price affects the final good price in the next period (since intermediate good is used to produce the final good with a lag).

In this context, an unanticipated fall in final demand - generated. for example. by an unanticipated fall in the money supply - has no immediate effect on final good prices (as these are precommitted). Consequently nominal wages, which depend on final good prices. do not adjust fully to the drop in final demand depend. Then intermediate good prices, which depend on nominal wages, do not adjust fully either (even when these prices are not precommitted). Furthermore, since next period's final good prices depend on the current intermediate good prices, the final good price level in the next period will fall less than proportionately to the initial drop in final demand. This. in turn. implies imperfect adjustment of next period's nominal wages. and so on.

Consequently a change in final product demand leads to a dynamic sequence of price changes in which the transient price precommitment gets transmitted from one period to the next. The resulting price inertia implies that the change in final product demand can have significant quantity effects.

\footnotetext{
"We are indebted to Ben Bernanke. Olivier Blanchard. Alan Blinder, Avinash Dixit, and Lars Svensson for their excellent comments. Support from the UK Employment Department (for the CEPR Program on "Labour Market Imperfections") and from the Johnsson Foundation. Sweden. is gratefully acknowledged.
} 
The assumptions underlying the model - (i) that final goods are produced by means of intermediate goods, (ii) that this production process involves lags. (iii) that nominal wages depend on final output prices, and (iv) that final output prices are precommitted when sales take place - are uncontroversial and plausible. The last assumption may. however. require some comment. Setting prices before sales are observed is a common phenomenon in practice. Department stores, supermarkets, automobile retailers, and furniture stores all attach prices to their products before customers decide whether to purchase them. The reason for this appears to be the existence of transactions costs and moral hazard problems. For example, if department stores would bargain over prices with each of their customers, there would be large negotiation costs and managers would have to relinquish control of pricing to their sales personnel. who may then be tempted to offer favorable terms to their families and friends.

Our explanation of price inertia merely requires that prices be precommitted in the initial period, when the unanticipated change in final demand occurs. In all subsequent periods, the precommitment assumption is unnecessary. It is sufficient that final output prices in, say, period 1 are not fully responsive to a final demand change in that period; for these output prices affect nominal wages in period 1 . which in turn affect intermediate good prices in that period, so that the output prices in period 2 will also be sluggish, and so on. Thus, even when final demand is known subsequent to the demand change in period 1 , the price inertia will not disappear.

It is important to emphasize that our particular model of price inertia involving a relation running from final output prices to nominal wages to intermediate input prices and back to final output prices - is merely one simple way of illustrating a far more general theory, in which any price precommitment combined with any production lags may lead to prolonged price inertia. To take another variant of the many conceivable models with the same basic idea, suppose for example that goods which satisfy final demands can also be used as intermediate inputs that produce further outputs with a lag. Then an unanticipated fall in final demand in the face of precommitted intermediate input prices will lead to inertia in the final output prices in the following period. But since these outputs are themselves used as intermediate inputs elsewhere, the next round of final output prices will also be characterized by inertia, and so on. Along these lines, the possibilities for generating price inertia associated with production lags are virtually endless. Our choice of production lag specification here merely serves to make our point in the simplest possible way.

Although it is certainly not surprising that prices are sluggish when producers do not respond to an unanticipated demand change, note that full immediate adjustment of prices to demand changes is practically inconceivable in our theoretical context. By "full immediate price adjustment" we mean an adjustment in which nominal wages. 
intermediate good prices, and final good prices all rise proportionately to the final demand change. so that this final demand change has no quantity effects. This is practically impossible to achieve when the current-period final output prices depend on the previous-period intermediate input prices. which in turn depend on the previous period nominal wages. which depend on the previous-period final output prices. and so on. Specifically, consider a fall in final demand occurring at the beginning of time period $t$. As shown below, the output prices in period $t$ will adjust fully immediately only if the prices of the associated intermediate inputs adjust fully immediately as well. Due to the production lag, however, these intermediate inputs must have been produced and bought in period $t-1$. Consequently, full, immediate adjustment of the intermediate input prices requires that the final demand increase be anticipated in period $t-1$. But the intermediate inputs in period $t-1$ are produced by labor, whose wage depends on the final output prices in period $t-1$, and the final outputs in period $t-1$ are themselves produced by intermediate inputs in period $t-2$, and so on indefinitely. Thus only a demand reduction that has been anticipated in the infinite past can generate full. immediate price adjustment. (Clearly, this feature is augmented when there are long chains of production. each associated with significant production lags, for then full price adjustment also requires that the demand change be anticipated all the way along the input-output chain.)

This feature also explains why it may be impossible to index intermediate input prices to the associated output prices. In the presence of production lags. current input prices would have to be indexed to future output prices. But the future output prices may be difficult, if not impossible, to predict since they in turn would have to be indexed to output prices lying even future in the furure, and so on.

Finally. the degree of price inertia generated by our model may be augmented by temporary nominal wage rigidities. To emphasize the role of production lags, we do not include such rigidities in our model. but it is easy to see that they would slow down the price adjustment process even further. The reason is that, in each round of the price adjustment process, nominal wages would be more sluggish, making concurrent intermediate good prices more sluggish, and thereby making final output prices more sluggish in the following period, and so on. Furthermore, the price inertia may in turn have an impact on the wage setting process, giving rise to further wage inertia. 1

The paper is organized as follows. Section 2 relates our contribution to the existing literarure on nominal rigidities. Section 3 presents the analytical building blocks of our model. On this basis Section 4 derives the associated price-quantity

TWhile Blanchard (1986) has modeled such an interaction based on wage-price staggering. our analysis suggests that both wage and price inertia can be greatly magnified through the operation of production lags. 
dynamics. Sections 5 and 6 then use this model to examine the price-quantity effects of temporary and permanent shifts in the product demand function. Section 7 concludes.

\section{Relation to the Literature}

As our theory is concerned with price dynamics in response to demand changes, it has the same domain of interest as menu costs, near-rationality, and wage-price staggering theories. 2 It is complementary with these theories in the sense that the price inertia generated by our theory may amplify and be amplified by menu costs. nearrationality, and wage-price staggering. 3 Yet unlike the menu cost and near-rationality theories, our model provides an explanation for why prices in practice are often changed frequently in the same direction. but not by sufficiently large amounts to obviate the need for significant quantity adjustments. ${ }^{4}$ Like the menu cost and near-rationality theories, our analysis seeks to explain why standard variations in aggregate demand can generate large output-employment fluctuations. But whereas the quantity effects of demand variations will not arise in the menu cost theory if, as appears plausible. the costs of output-employment adjustment exceed the cost of price adjustment. this is not the case for price inertia generated by production lags. 5

In contrast to the staggering theory, our theory makes the degree of price inertia depend on technologically given production lags rather than on contract periods. 6 It is worth noting that our theory is not only complementary to the staggering theory: production lags may indeed provide a new rationale for price staggering: i technological reasons these lags are not perfectly synchronized across productin sectors and thus the corresponding pricing decisions will not be perfectly synchronized as well. 7

The seminal contributions include Akerlof and Yellen (1985) and Mankiw (1985), Phelps and Taylor (1977), Taylor (1979), and others.

3The complementarity with the staggering theory was noted in the previous section. Basu (1995) shows how the effects of menu costs become more pronounced when they interact alorg chains of production in an input-output system. Menu costs within our analytical tranework could be used to explain how even perfectly anticipated final demand changes can become associated with price inertia and significant quantity effects.

tSince the menu costs of large price changes do not appear to be significantly greater than those of small price changes, it is not clear how the menu cost theory can account for this phenomenon.

5 This is easy to show in the analytical framework below, although for brevity we do not do so.

6The staggering theory requires that the length of price contracts is "sluggish" in response to demand changes (for otherwise changes in contract length would obviate the need for quantity adjustments): our theory requires that the length of the production lag is "sluggish" in this respect.

7 This is not the way price staggering has been rationalized in the current literature. Ball and Cecchetti (1988) do so via firms' incentive to gain information about their 
Our theory also has common objectives with the contributions that rationalize price inertia by showing how demand shocks are cushioned by movements of inventories and order backlogs. ${ }^{8}$ These theories should be observationally distinct from ours. however. since the dynamics of inventories and order backlogs are generally distinguishable from production lags.

Our theory is inspired by the well-known idea that the price inertia of a good depends on how roundabout is the process whereby that good is produced. This idea dates back at least to Means (1935), who showed that in the Great Depression complex manufactured goods were characterized by smaller price fluctuations and larger quantity fluctuations than simple manufactured goods or, even more so, primary products. More recently, corroborating evidence has been provided by Carlton (1986). Gordon (1990) has suggested that firms' inability to predict cost variations within a complex input-output system causes them systematically to underestimate the magnitude of nominal demand changes, so that price inertia results. 9 Our theory differs from Gordon's hypothesis by focusing on production lags, rather than assuming systematic expectational errors, as central determinant of price inertia. Even more recently, Basu (1995) has shown how the existence of intermediate goods in an input-output system magnifies the price rigidity arising from menu costs. Although. as noted, our model could generate this conclusion as well. our theory has a different focus from Basu's. We are concerned with the derivation of price dynamics in response to demand changes, whereas Basu is concerned with the range of demand shocks over which prices are rigid; we focus on production lags. while Basu's analysis is static; in our model price variations are time-dependent, whereas in Basu's they are state-dependent.

In sum, while existing contributions show how the degree of price inertia may depend on the length of contract periods and on small costs of price change. these contributions do not relate price dynamics to the characteristics of production processes. Moreover, while other contributions show intermediate goods in input-output systems may contribute to price rigidity, these contributions are not concerned with production lags and the associated dynamic process of price change. It is here that the

rivals' prices before setting their own prices. Ball and Romer (1989) rationalize it by supposing that there are firm-specific shocks falling on different firms at different times.

${ }^{8}$ Blinder (1981) and others.

$9 " .$. the typical firm has no idea of the identity of its full set of suppliers when all the indirect links within the input-output table are considered. Because the informational problem of trying to anticipate the effect of a currently perceived nominal demand change on the weighted average costs of all these suppliers is difficult to formulate and probably impossible to solve ... the sensible firm just waits by the mailbox for news of cost increases and then, Okun-like, passes them on a price increases" (Gordon, 1990, pp.1150-1). 
focus of our theory lies.

\section{Analytical Building Blocks}

Our model economy produces one intermediate good and several final (consumption) goods. The intermediate good $I$ is produced by means of labor $L$ with a Cobb-Douglas technology:

$$
I_{\mathrm{t}}=L_{\mathrm{i}}^{\mu}
$$

where $\mu$ is a constant $(0<\mu<1)$. There are $\Phi$ intermediate-good producers, each of whom is a price-taker, maximizing profit $P_{\mathrm{t}} \cdot I_{\mathrm{t}}-W_{\mathrm{t}} \cdot L_{\mathrm{t}}$ subject to the production function (1). while taking the intermediate good price $P_{\mathrm{t}}$ and the nominal wage $W_{\mathrm{t}}$ as exogenous to the output $\left(I_{\mathrm{t}}\right)$ and employment $\left(L_{\mathrm{t}}\right)$ decisions. The resulting labor demand $\left(L_{\mathrm{t}}^{\mathrm{d}}\right)$ and intermediate good supply $\left(I_{\mathrm{t}}^{\mathrm{s}}\right)$ of each intermediate-good producer are

$$
\begin{aligned}
& L_{\mathrm{t}}^{\mathrm{d}}=\left(\frac{W_{\mathrm{t}}}{P_{\mathrm{t}} \cdot \mu}\right)^{\frac{1}{1-\mu}} \\
& I_{\mathrm{t}}^{\mathrm{s}}=\left(\frac{W_{\mathrm{t}}}{P_{\mathrm{t}} \cdot \mu}\right)^{-\frac{\mu}{1-\mu}}
\end{aligned}
$$

There are $F$ differentiated final goods, each produced by a different firm. Each firm faces symmetric demand and cost conditions. For simplicity, let the representative firm produce the final good $q_{\mathrm{t}}^{\mathrm{s}}$ by means of only the intermediate good $I_{\mathrm{r}}$. The technology is again Cobb-Douglas, but now there is a one-period production lag: 10

$$
q_{t+1}^{s}=I_{t}^{\gamma}
$$

where $\gamma$ is a constant $(0<\gamma<1)$.

Each final good producer is a Cournot oligopolist. ${ }^{11}$ taking other firms ${ }^{*}$ quantities

10We scale $L_{\mathrm{r}}, I_{\mathrm{r}}$ and $q_{\mathrm{t}}$ so that the multiplicative constants in the production functions (1) and (3) are unity.

11 As explained in footnote 14. qualitative conclusions remain intact under other types of oligopolistic interactions. 
as given when making its own price-quantity decisions $\left(p_{t}\right.$ and $\left.q_{\mathrm{t}}\right)$. Given the aggregate price index $\pi_{t}$ of the final good and the nominal money supply $M_{t}$, let the demand for the firm's product have the following constant-elasticity form:

$$
q_{\mathrm{t}}^{\mathrm{d}}=\alpha \cdot\left(\frac{M}{\bar{\Pi}_{\mathrm{t}}}\right)^{\varepsilon} \cdot\left(\frac{p_{\mathrm{t}}}{\bar{\Pi}_{\mathrm{t}}}\right)^{-\eta}
$$

where $\alpha, \varepsilon$, and $\eta$ are positive constants.

In any period $t=\tau$, each final good producer decides to purchase $I_{\tau}$ intermediate goods in order to produce output $q_{\tau+1}$ at price $p_{\tau+1}$, taking the nominal wage $W_{\tau}$ and the intermediate input price $P_{\tau}$ as predetermined. In short, the decisions $\left(I_{\tau}, q_{\tau+1}, p_{\tau-1}\right)$ are all made in period $\tau$. Let $\Pi_{\tau}^{\mathrm{e}(\mathrm{t})}$ be the aggregate price level of final goods in period $\tau$ that the final good producer expects in period $t$, and let $\delta$ be the producer's real discount factor. Then, in any period $t$, each final good producer seeks to maximize the following real present value of profit $\left(z_{\mathrm{t}}\right)$ :

$$
z_{\mathrm{t}}=\sum_{\tau=1}^{\infty} \delta^{\tau+1} \cdot \frac{p_{\tau+1} \cdot q_{\tau+1}}{\Pi_{\tau+1}^{\mathrm{e}(\tau)}}-\delta^{\tau} \cdot \frac{P_{\tau} \cdot I_{\tau}}{\Pi_{\tau+1}^{\mathrm{e}(t)}}
$$

subject to the production function (3) and the final product demand function (4). 12

The objective function (5) is standard, but it may nevertheless be useful to review how the inputs and outputs are valued. since it may appear at first glance that the input is valued at historical cost rather than opportunity cost. Following Malinvaud (1972, p.253) and others. the general expression for the present value of a firm's nominal profit $\left(Z_{\mathrm{t}}\right)$ is

$$
Z_{\mathrm{t}}=\sum_{\tau=\mathrm{t}}^{\infty} \delta^{\tau} \cdot\left[\mathbf{p}_{\tau} \cdot \mathbf{q}_{\tau}-\mathbf{p}_{\tau} \cdot \mathbf{a}_{\tau}\right]
$$

where $\mathbf{p}_{\tau}$ is a vector of prices of all the commodities going through the firm's production process, and $\mathbf{q}_{\tau}$ and $\mathbf{a}_{\tau}$ are the corresponding vectors of all the firm's outputs and inputs. With respect to our analysis. $\mathbf{p}_{\tau}=\left(p_{\tau}, P_{\tau}\right)^{\prime}, \mathbf{q}_{\tau}=\left(q_{\tau} .0\right)$, and $\mathbf{a}_{\tau}=$ $\left(0, I_{\tau}\right)$; moreover, $\mathbf{q}_{\mathrm{r}}=(0,0)$. since there is no output in the first period of

T-Note that expectations formulated prior to period $t$ are not relevant to the producer's maximization problem, since it is only in period $t$ that the output and pricing decisions for period $t$ are made. 
production. Since the production process lasts one period. $q_{t}=0$. Making these substitutions into $\left(5^{\prime}\right)$ yields the nominal counterpart of our objective function $(5): Z_{t}$ $=\sum_{\tau=1}^{\infty}\left(\delta^{\tau-1} \cdot p_{\tau-1} \cdot q_{\tau+1}-\delta^{\tau} \cdot P_{\tau} \cdot I_{\tau}\right)$

To show that this objective function contains the appropriate valuation of inputs in terms of their opportunity costs, observe that since the decisions $\left(I_{\tau}, q_{\tau-1}\right.$. $\left.p_{\tau+1}\right)$ are all made in period $\tau$, the inputs should be valued in terms of their opportunity costs at date $\tau$. The opportunity cost of the intermediate input $I_{\tau}$ at date $\tau$ is $P_{\tau}{ }^{13}$ (It is clearly not appropriate to value the intermediate input $I_{\tau}$ in terms of its opportunity cost at time $\tau+1$, when the revenues generated by that input accrue. That opportunity cost is generally around zero, since at date $\tau+1$ the intermediate good is already embodied in the output and can no longer be extracted in its original form to be used as intermediate input elsewhere. 1415 )

To express the nominal present value $Z_{\mathrm{t}}=\sum_{\tau=\mathrm{t}}^{\infty}\left(\delta^{\tau+1} \cdot p_{\tau+1} \cdot q_{\tau+1}-\delta^{\tau} \cdot P_{\tau} \cdot I_{\tau}\right)$ in real terms involves deflating both the period $\tau$ cost $\left(P_{\tau} I_{\tau}\right)$ and the period $\tau+1$ revenue $\left(p_{\tau+1} \cdot q_{\tau+1}\right)$ by the period $t$ expectation of the aggregate price level in period $\tau+1$ : $\Pi_{\tau+1}^{e}(t)$. The reason is that if the firm seeks to maximize the purchasing power of its profits through time, it needs to detlate the profit in each time period by the aggregate price index that is expected to prevail in the period when this profit accrues. 16 For example, suppose that the firm lives for just two periods, 0 and 1 . so

13This is true regardless of whether the intermediate goods are purchased at the time when they enter the production process (as in our model) or whether they have been purchased previously.

${ }^{14}$ For example, the opportunity cost of chrome on car fenders and cinnamon in cookies is nil since these intermediate goods can no longer be separated from the goods they are in.

15 If our model were to contain inventories carried forward from period $\tau$ to period $\tau+1$, such as gasoline inventories at gas stations, then they would clearly have to be valued in terms of their opportunity costs at time $\tau+1$, as implied by $\left(5^{\prime}\right)$. Letting $k_{\tau}$ and $k_{\tau+1}$ be the stocks of inventories of the produced good at dates $\tau$ and $\tau+1$. respectively, the relevant valuation is $\sum \delta^{\tau+1} \cdot \mathrm{p}_{\tau+1} \cdot \mathrm{k}_{\tau+1} \cdot \delta^{\tau} \cdot \mathrm{p}_{\tau} \cdot \mathrm{k}_{\tau}$. Thus our analysis is quite consistent with the view that the retail price of gasoline jumps immediately after a disturbance in oil production, even though the crude oil used to produce the gasoline that was being sold had been purchased at a lower price.

16 Alternatively, if the firm. making its decisions $\left(I_{\tau}, q_{\tau+1}, p_{\tau+1}\right)$ at time $\tau$. seeks to maximize the present value of its profit at time $t$, then all its profits through time must be deflated by the aggregate price level in period $t$ that the firm expects in period $t: \pi_{t}^{(t)}$. It is easy to show. however, that this deflator leads to the same price dynamics equation as the deflator above. (The reason is that, as long as the revenue term $\delta^{\tau+1} \cdot p_{\tau+1} \cdot q_{\tau+1}$ is deflated by the same aggregate price deflator as the cost term 
that its nominal profit is $-P_{0} \cdot I_{0}+\delta \cdot p_{1} \cdot q_{1}$. Since the input, output, and pricing decisions are all made at time $t=0$ while the profit accrues at time $t=1$. nominal profit must be deflated by $\pi_{1}^{\mathrm{e}(0)}$ in order to obtain real profit.

Defining $e \equiv 1-1 / \eta$, where $1 / \eta$ is Lemer's index of monopoly power, the intermediate good producer's first-order condition for profit maximization is 17

$$
\delta \cdot \mathrm{e} \cdot \gamma \cdot \mathrm{I}_{\tau}^{\gamma-1}=\frac{P_{\tau}}{p_{\tau+1}} \quad \text { for } \tau \geq t
$$

which means that the discounted marginal revenue product of the intermediate input (the left-hand expression) is equal to the real factor cost (the right-hand side expression). 18

Since all final goods producers face symmetric demand and cost conditions, they all charge the same price $p_{\mathrm{t}}$ in equilibrium and thus the aggregate price index is $\Pi_{\mathrm{t}}=p_{\mathrm{t}}$.

Finally, to focus attention on how price inertia can arise from production lags in an input-output system, rather than from nominal wage rigidities, we assume such nominal rigidities away by supposing quite simply that the real wage $\left(w_{\mathrm{t}}\right)$ is constant through time: 19

$$
w_{\mathrm{t}}=W_{\mathrm{t}} / \Pi_{\mathrm{t}}=w
$$

On this basis we now proceed to derive the price-quantity dynamics for our model economy.

$\delta^{\tau} \cdot P_{\tau} \cdot I_{\tau}$, the first-order condition of the final good producer will still be (6).)

${ }_{17}$ While this condition presupposes monopolistic competition, other forms of imperfect competition among firms yield a similar first-order condition. For example, supposing that the final goods produced by the $F$ firms are all homogeneous, the oligopolistic interactions among firms may be summarized by $\left(\partial Q_{\mathrm{t}}^{\mathrm{e}} / \partial q_{\mathrm{t}}\right)=\xi$, where $Q_{\mathrm{t}}^{\mathrm{e}}$ is the aggregate output expected by the firm and $\xi$ is a positive constant: under cartel behavior, $\xi=F$; under Cournot behavior $\xi=1$ : and under Bertrand (perfectly competitive) behavior, $\xi=$ 0 . Then the first-order condition for profit maximization is (6), where the monopoly power parameter is redefined as $e=1-\xi / \eta$.

$18 \mathrm{We}$ implicitly assume that, in any time period $\tau$, the firm has an incentive to use its intermediate inputs to produce output rather than to hold them as inventories. i.e. the profit from using the intermediate good to produce the output $\left(\delta \cdot p_{\tau+1} q_{\tau+1}-P_{\tau} I_{\tau}\right)$ is greater than the capital gain from holding the intermediate good $\left(\delta \cdot P_{\tau+1} \cdot I_{\tau}-P_{\tau} \cdot I_{\tau}\right)$ This condition reduces to $\left(P_{\tau+1} / P_{\tau}\right)<(1 / \delta) \cdot[1+(1-\mathrm{e} \cdot \gamma) /(\mathrm{e} \cdot \gamma)]$, where $(1 / \delta) \cdot[1+(1$ $-\mathrm{e} \cdot \gamma) /(\mathrm{e} \cdot \gamma)]>1$.

${ }^{19}$ This real wage may. for example, be viewed as the workers' reservation wage. 


\section{Price-Quantity Dynamics}

The price-quantity dynamics in our model may be derived from the market-clearing conditions for the intermediate good and the final goods. Using "^" to denote logarithms of variables, and recalling that $p_{\mathrm{t}}=\pi_{\mathrm{t}}$ in equilibrium. the market-clearing condition for each final good $\left(q_{\mathrm{t}}^{\mathrm{s}}=q_{\mathrm{t}}^{\mathrm{d}}=q_{\mathrm{t}}\right)$ is

$$
\hat{q}_{\mathrm{t}+1}=\gamma \hat{I}_{\mathrm{t}}=\hat{\alpha}+\varepsilon \cdot\left(\hat{M}-\hat{\Pi}_{\mathrm{t}+1}\right)
$$

by the production function (3) and the demand function (4).

We now derive the market-clearing condition for the intermediate good. By equations (2b) and (7) and recalling that there are $\Phi$ intermediate good producers, the aggregate supply of the intermediate good in period $t$ becomes

$$
\hat{\Gamma}_{\mathrm{t}}=\hat{\Phi}+\frac{\mu}{1-\mu} \cdot\left(\hat{\mu}-\hat{w}-\hat{\Pi}_{\mathrm{t}}+\hat{P}_{\mathrm{t}}\right)
$$

Given the first-order condition (6) and recalling that there are $F$ final good producers. the aggregate demand for the intermediate good becomes

$$
\hat{I}_{\mathrm{t}}^{\mathrm{d}}=\hat{F}+\frac{1}{\Gamma-\gamma} \cdot\left(\hat{\delta}+\hat{e}+\hat{\gamma}-\hat{P}_{\mathrm{t}}+\hat{\Pi}_{\mathrm{t}+1}\right)
$$

Thus the market clearing condition for the intermediate good $\left(\hat{I}_{\mathrm{t}}^{\mathrm{s}}=\hat{I}_{\mathrm{t}}^{\mathrm{d}}=\hat{I}_{\mathrm{t}}\right)$ may be expressed as

$$
\hat{I}_{\mathrm{t}}=\frac{\mu}{I-\mu \cdot \gamma} \cdot\left(\left[\hat{\Pi}_{t+1}-\hat{\Pi}\right)+(\hat{\delta}+\hat{e}+\hat{\gamma}+\hat{\mu-w})+(1-\gamma) \cdot \hat{F}+\left(\frac{1-\mu}{\mu}\right) \cdot \hat{\Phi}\right)
$$

Substituting the market-clearing condition for the final good (8) into that for the intermediate good (11), we obtain the following price dynamics function:

$$
\hat{\Pi}_{t+1}=a \cdot \hat{\Pi}_{t}+(1-a) \cdot \hat{M}+b
$$

where the money supply $M$ is taken as a time-invariant parameter, and 


$$
\begin{gathered}
a \equiv \frac{\mu \cdot \gamma}{\mu \cdot \gamma+\varepsilon \cdot(1-\mu \cdot \gamma)} \\
\left.b=a \cdot(\hat{\delta}+\hat{e}+\hat{\gamma}+\hat{\mu} \cdot \hat{w})+(1-\gamma) \cdot \hat{F}+\left(\frac{1-\mu}{\mu}\right) \cdot \hat{\Phi}-\frac{\hat{\alpha}}{\gamma}\right)
\end{gathered}
$$

The coefficient $a$, which we call the "price inertia coefficient", measures the degree to which last period's prices affect current prices. Recalling that $0<\mu, \gamma<1$. it follows that $0<a<1.20$

The time path of prices, given by the solution to the difference equation (12), is

$$
\hat{\pi}_{\mathrm{t}}=\left(\hat{M}+\frac{b}{1-a}\right) \cdot\left[1-a^{\mathrm{t}}\right]+\hat{\pi}_{0} \cdot a^{\mathrm{t}}
$$

assuming that $a \neq 1$. The corresponding output trajectory may be found by substituting equation (14) into the aggregate final demand function and letting $\hat{p}_{\mathrm{r}}=\hat{\pi}_{\mathrm{r}}$ :

$$
\hat{q}_{\mathrm{t}}=\hat{\alpha}+\varepsilon \cdot\left(\hat{M}-\hat{\Pi}_{\mathrm{t}}\right)=\left(M-\Pi_{0}\right) \cdot a^{t}-\frac{b}{1-a} \cdot\left(1-a^{t}\right)
$$

In this context, we now examine the price-quantity effects of permanent and temporary shifts in product demand.

\section{Price Sluggishness: The Effects of a Permanent Demand Shift}

We define "price sluggishness" as occurring when a permanent demand shift has delayed effects on the price level. To fix ideas, let the permanent demand shift take the form of a permanent fall in the money supply $M$ in period 0 . Then price sluggishness occurs whenever the price level $\pi_{t}$ falls less than proportionately to the money supply in subsequent periods, so that it takes some time for the level of real money balances $\left(M / \pi_{\mathrm{t}}\right)$ to be restored to its long-run equilibrium level.

Specifically, consider the following sequence of events. Initially. at the beginning of period $t=0$, the money supply is $\hat{M}_{0}$, the price level is at its corresponding

20 The condition that $a<1$ can be shown to be equivalent to the condition that $E \cdot[1 /(1-$ $\gamma)] \cdot[1+(1 /(1-\gamma) \cdot(1-\mu) / \mu]>0$. 
stationary equilibrium level $\left(\hat{\Pi}_{0}=\hat{M}_{0}+[b /(1-a)]\right)$, as is the output and price of the intermediate good. Then, in the course of period $t=0$ - while the intermediate good $\hat{I}_{0}$ is being used to produce the final good $\hat{q}_{1}$ - the money supply falls to $\hat{M}_{1}\left(<\hat{M}_{0}\right)$ and remains at this new level thereafter. This permanent monetary shock is unforeseen at the beginning of period $t=0$ and thus does not affect the price-quantity decisions made at the beginning of that period. with regard to both the final and the intermediate good.21 From period 2 onwards, however, the price-quantity decisions concerning the intermediate and final goods take the monetary shock into account.

Then, by (14), the price effects of the permanent monetary shock are

$$
\frac{\mathrm{d} \hat{\Pi}_{\mathrm{t}}}{\mathrm{d} \hat{M}}=1-a^{\mathrm{t}}
$$

for $t>1$, where $d \hat{\Pi}_{t}$ is the difference between the price level in period $t$ in the presence and absence of the monetary shock. Equation (16) implies that $\left(\mathrm{d} \Pi_{t} / \mathrm{d} \hat{M}\right)$ is positive, less than unity, but asymptotically approaches unity. This means that the permanent monetary fall leads to a sequence of price decreases that eventually restore real money balances $\left(\mathrm{M} / \pi_{\mathrm{t}}\right)$ to their initial stationary equilibrium level.

By (15), the quantity effects of the permanent monetary shock are

$$
\frac{\mathrm{d} \hat{q}_{\mathrm{t}}}{\mathrm{d} \hat{M}}=\varepsilon \cdot\left(1-\frac{\mathrm{d} \hat{\Pi}_{\mathrm{t}}}{\mathrm{d} \hat{M}}\right)=\varepsilon \cdot a^{\mathrm{t}}
$$

for $t>1$. Observe that $\left(\mathrm{d} \hat{q}_{\mathrm{t}} / \mathrm{d} \hat{M}\right)>0$ and $\left(\mathrm{d} \hat{q_{\mathrm{r}}} / \mathrm{d} \hat{M}\right) \rightarrow 0$ as $\mathrm{t} \rightarrow \infty$, so that when the money supply falls, output first declines and then returns asymptotically to its initial level.

The underlying mechanism illustrated in Figure 1 , which pictures the price dynamics function (12) as a line mapping $\hat{\Pi}_{t}$ into $\hat{\Pi}_{t+1}$. In period $t=0$ this line is $P C_{0}$ and the economy is at the corresponding long-run equilibrium point $A$. The permanent fall in the money supply shifts the price dynamics line downwards to $P C_{1}$ in period $t=1$ and keeps it there for all subsequent periods. Given that the final good prices are precommitted in period $t=1$, the period 1 price level remains at $\hat{\Pi}_{0}$. In the following

21 The assumption that the shock is not anticipated until it occurs is not essential to the qualitative conclusions of our analysis. If the shock were anticipated in some previous period, the effects of the shock would gradually start making themselves felt then. Prices would still be sluggish and the final equilibrium, in which prices change proportionately to the money supply, would still be approached asymptotically. 
period $(t=2)$, the final good price falls by the vertical distance from $A$ to $B_{1}$. This leads to a corresponding fall in the nominal wage and the intermediate good price in period $t=2$. and thus the final good price in period $t=3$ falls by the vertical distance from $B_{1}$ to $B_{2}$, and so on. This chain reaction of price reductions continues until the economy eventually reaches its new long-run equilibrium point $D$. In this way. a temporary rigidity in the pricing of intermediate goods turns into prolonged price sluggishness.

As Figure 1 implies, all that the model requires for this to happen is that the price inertia coefficient $a$ be positive, 22 which (by (13a)) is the case when the production functions (1) and (3) display diminishing returns $(0<\mu, \gamma<1)$ and the elasticity of product demand $(\varepsilon)$ is finite. Observe that $(\partial a / \partial \mu),(\partial a / \partial \gamma)>0$ and $(\partial a / \partial e)<0$. Thus, the more slowly the returns to the productive factors diminish (i.e. the greater are $\mu$ and $\gamma$ ) and the lower is the elasticity of product demand $(\varepsilon)$. the greater is the price inertia coefficient (the slope of the price dynamics line): consequently the greater is the degree of price sluggishness. 23 Specifically. the greater is the price inertia coefficient, the longer it takes for a fraction $\kappa$ of the full price effect to manifest itself.

Figure 2 a provides further intuitive understanding of these results by picturing the movement of the final good producer's marginal revenue and marginal cost curves. together with the resulting price-quantity decisions. The inverted demand curve (in log form) is given by

$$
\hat{p}_{\mathrm{t}}=\hat{M}+\frac{1}{\varepsilon}(\hat{\alpha}-\hat{q})
$$

where $p_{\mathrm{t}}=\Pi_{\mathrm{t}}$ in equilibrium. Thus the final producer's revenue is $R=\alpha^{1 / \varepsilon} M q^{-(1-\varepsilon) / \varepsilon}$, and the marginal revenue (in $\log$ form) is

$$
M R=\hat{M}+\zeta_{1}+\frac{1}{\varepsilon}(\hat{\alpha}-\hat{q})
$$

where $\zeta_{1}=\log (1-(1 / \varepsilon))$ is a constant. The final producer's total cost is $C=$ $P_{t-1}(1 / \gamma) q^{(1-\gamma), \gamma}$, and thus the marginal cost (in $\log$ form) is

22Clearly, if $a=0$, full adjustment takes place within a period of the monetary shock. 23 Observe that the degree of monopoly power $(e)$ of the final good producers affects the intercept $b$, but not the slope $a$, of the price dynamics line (12). Thus the greater the degree of monopoly power (ceteris paribus), the greater will be the price level. while the degree of price sluggishness remains unchanged. 


$$
M C=\hat{P}_{t-1}+\zeta_{2}+\frac{1-\gamma}{\gamma} \hat{q}
$$

where $\zeta_{2}=\log (1 / \gamma)$ is a constant.

The initial demand curve (Equation 18) is given by $D_{0}$ in Figure 2a. and the marginal revenue and marginal cost curve are denoted by $M R_{0}$ (Equation 19) and $M C_{0}$ ) (Equation 20), respectively. Thus the initial price-quantity decision (in the initial stationary equilibrium) is given by point $A$. Then comes the permanent monetary shock, occurring in the course of period 0 , and not anticipated until it occurs. The marginal revenue and marginal cost curves, $M R_{0}$ and $M C_{0}$, that all relevant to the price-quantity decision $\left(p_{1}, q_{1}\right)$ made at the beginning of period 0 , are not affected since the monetary shock is not known at the beginning of period 0 . Thus the price $p_{1}$ and quantity $q_{1}$ remain at their initial equilibrium levels.

Now consider the decisions $\left(p_{2}, q_{2}\right)$ made at the beginning of period 1 . The rele'ant marginal revenue curve shifts down from $M R_{0}$ to $M R_{1}$, in proportion to the drop in the money supply. The marginal cost curve, however, shifts down less than proportionately. from $M C_{0}$ to $M C_{1}$. The reason is that the period-1 intermediate goods. that are used to produce the period-2 final goods, depend on the period-1 final good prices (via the nominal wage) and these latter prices are sticky. Since the marginal revenue curve shifts downward by more than marginal cost curve. the price of the final good falls from $p_{1}$ to $p_{2}$ and the final output falls from $q_{1}$ to $q_{2}$. This price-quantity decision is denoted by point $B_{1}$ in Figure $2 \mathrm{a}$ (analogous to $B_{1}$ in Figure 1).

In all subsequent periods the drop in the final good price level leads to a proportional fall in the nominal wage, and this in turn leads to a tall in the intermediate good price. As result the marginal cost curve shifts downwards (as shown by the arrow below the $M C_{1}$ curve) along the stable marginal revenue curve $M R_{1}$. By implication, the final good price falls towards its long-run equilibrium value $p_{\infty}$ and final output gradually returns to its initial equilibrium level $q_{0}$. The long-run pricequantity point is denoted by point $D$ in Figure 2 a (analogous to point $D$ in Figure 1).

(The appendix explains this dynamic process explicitly in terms of the interaction between the final-good and intermediate-good markets.)

To summarize.

Proposition 1: When the production functions of the final and intermediate good producers are characterized by positive, but diminishing, returns $(0<\mu . \gamma<1)$ and the wealth elasticity of product demand $(\varepsilon)$ is finite, a permanent drop in the money supply. occurring in period 0 , has the following price-quantity effects, sturting from an initial stationary equilibrium: 
(i) the price level falls asymptotically to its new stationary equilibrium level, and

(ii) the quantity transacted falls beneath its initial level in period 1 and then rises asymptotically back to that level.

\section{Price Persistence: The Effects of a Temporary Demand Shift}

We define "persistence" in price setting as occurring when a temporary demand shift has prolonged effects on the price level. Specifically, let the temporary demand shift take the form of a drop in the money supply in period 0 , reversing itself at the beginning of period 2 , when it returns to its original level and remains there. Then there is persistence in price setting if, starting from an initial stationary equilibrium price level $\hat{\Pi}_{0}$ in period 0 , the price level remains below $\hat{\Pi}_{0}$ for more than two periods.

As above, the drop in the money supply occurs in the course of period 0 and is not anticipated by agents making their decisions before then. Thus in period 0 the price and quantity of the intermediate good is not affected; nor is the period-1 price of the final good (since it is precommitted) or the period-1 final output (since the output supply decision was made in period 0 , when the intermediate inputs were purchased).

Then, in the context of our model, it can indeed be shown that, if the production functions of the final and intermediate good producers are characterized by positive. but diminishing returns $(0<\mu, \gamma<1)$ and the wealth elasticity of product demand $(\varepsilon)$ is finite - so that the price inertia coefficient $a$ is less than unity - the temporary monetary shock $\left(\mathrm{d} \hat{M}_{1}=\hat{M}_{1}-\hat{M}_{0}\right)$ causes the price level in period 2 to fall less than proportionately to the money supply and then to return gradually to its long-run stationary level. By (14), the price effects of the temporary monetary shock are

$$
\frac{\mathrm{d} \hat{\Pi}_{\mathrm{t}}}{\mathrm{d} \hat{M}_{1}}=(1-a) \cdot a^{\mathrm{t}-1}
$$

for $t>1$, where $\hat{d}_{t}$ is again the difference between the final good price level in period $t$ in the presence and absence of the monetary shock. Observe that $\left(\mathrm{d} \Pi_{t} / \mathrm{d} M_{1}\right)$ is positive, less than unity. and asymptotically approaches zero. This means that the temporary monetary shock generates persistent price effects that gradually die out.

To derive the corresponding quantity effects, observe that when the temporary monetary shock occurs in period 0 and remains at its new level until period 2 (when it reverses itself), the quantity demanded in period 2 is affected directly by $\mathrm{d} \hat{M}_{1}$ and 
indirectly by the influence of $\mathrm{d} \hat{M}_{1}$ on $\mathrm{d} \Pi_{i}: 24$

$$
\frac{\mathrm{d} q_{2}}{\mathrm{~d} \hat{M}_{1}}=\varepsilon \cdot\left(1-\frac{\mathrm{d} \hat{\Pi}_{1}}{\mathrm{~d} \hat{M}_{1}}\right)=\varepsilon \cdot(1-(1-a) \cdot a) \text { for } t=2
$$

In all subsequent periods. when the monetary shock has disappeared. the quantity effects can occur only via the delayed price responses to the shock:

$$
\frac{\mathrm{d} q_{\mathrm{t}}}{\mathrm{d} \hat{M}_{1}}=-\varepsilon \cdot \frac{\mathrm{d} \hat{\Pi}_{\mathrm{t}}}{\mathrm{d} \hat{M}_{1}}=-\varepsilon \cdot(1-a) \cdot a^{\mathrm{t}-1} \quad \text { for } t>2
$$

Since $\left(\hat{\mathrm{d}}_{2} / \mathrm{d} \hat{M}_{1}\right)>0$ and $\left(\hat{\mathrm{d}}_{\mathrm{t}} / \mathrm{d} \hat{M}_{1}\right)<0$ for $t>2$. a temporary fall in the money supply initially reduces final product demand and subsequently overshoots its long-run level.

Figure 1 illustrates the chain reaction of price effects. The economy is initially at the long-run equilibrium point $A$. whereupon the price dynamics line shifts downwards from $P C_{0}$ to $P C_{1}$ in period 1 and then returns to $P C_{0}$ for all subsequent periods. Due to precommitment, the period 1 price level remains at $\pi_{0}$, and in period 2 the final good price falls by the vertical distance from $A$ to $B_{1}$. This results in a fall in the nominal wage and the intermediate good price in period 2. At the same time. the price dynamics line shifts back from $P C_{1}$ to $P C_{0}$. Since the upward shift of the price dynamics line is proportional to the rise in the money supply whereas the fall in the intermediate good price is less than proportional to the previous fall in the money supply, and thus the price of the final output in period 3 rises less than proportionately to the rise in the money supply (depicted by the vertical distance from $B_{1}$ to $C_{1}$ ). This, in turn, leads to a rise in the nominal wage and the intermediate good price in period 3. and consequently the final good price in period 4 rises by the vertical distance from $C_{1}$ to $C_{2}$. This process continues until the economy eventually returns to its initial stationary equilibrium point $A$. As the figure implies. the steeper is the slope of the price dynamics line (i.e. the greater is the price inertia coefficient $a$ ), the more persistent will these price effects be.

Figure $2 b$ illustrates this dynamic process in terms of the final good producer's marginal revenue and marginal cost curves. The price-quantity decision in the initial equilibrium is given by point $A$ in the figure. Then comes the temporary drop in the money supply, occurring in the course of period 0 and reversing itself at the beginning

27 Recall that the quantity demand in period 1 is precommitted. 
of period 2. Once again, the marginal revenue and marginal cost curves. $M R_{t}$ and $M C_{1)}$, that are relevant to the price-quantity decision $\left(p_{1}, q_{1}\right)$ made at the beginning of period 0 , are not affected, and thus the price $p_{1}$ and quantity $q_{1}$ remain at their initial equilibrium levels.

Turning to the decisions $\left(p_{2}, q_{2}\right)$ made at the beginning of period 1 , the relevant marginal revenue curve shifts down from $M R_{0}$ to $M R_{1}$, in proportion to the drop in the money supply. The marginal cost curve shifts down less than proportionately, from $M C_{1)}$ to $M C_{1}$. (As in the previous section, the reason is that the period-1 intermediate goods depend on the period-1 final good prices, via the nominal wage, and these latter prices are precommitted.) Since the marginal revenue curve shifts downward by more than marginal cost curve, the price of the final good falls from $p_{1}$ to $p_{2}$ and the final output falls from $q_{1}$ to $q_{2}$. This price-quantity decision is denoted by point $B_{1}$ in the figure (corresponding to point $B_{1}$ in Figure 1).

Thereafter the money supply returns to its original level, so that the demand curve and marginal revenue curve also return to their original positions. $D_{0}$ and $M R_{0}$. respectively. The marginal cost curve, however, does not return to its original position. since the intermediate good price depends (in part) on the final good price (via the nominal wage), and the latter price falls in period 2 . Thus the marginal cost curve rises less (from $M C_{1}$ to $M C_{2}$ in the Figure $2 \mathrm{~b}$ ) than the marginal revenue curve (from $M R_{1}$ to $M R_{10}$ ). For this reason, the final output rises above its initial equilibrium to $q_{i}$. The new price-quantity decision is denoted by point $C_{1}$ in Figure $2 b$ (corresponding to point $C_{1}$ in Figure 1).

In all subsequent periods, the marginal cost curve continues to rise along the stable marginal revenue curve $M R_{0}$, so that the price-quantity combination gradually returns its initial equilibrium at point $A$.

(As in the case of the permanent shock, the appendix explains this dynamic response to the temporary shock explicitly in terms of the interaction between the tinal-good and intermediate-good markets.)

In sum.

Proposition 2: When the production function of the final and intermediate good producers are characterized by positive, but diminishing returns $(0<\mu, \gamma<1)$ and the elasticit. of product demand $(\varepsilon)$ is finite, a temporary drop in the money supply, occurring in period $\mathrm{O}$, has the following price-quantity effects, starting from an initial stationary equilibrium price-quantity combination $\left(\hat{\Pi}^{\mathrm{o}}, \hat{q}^{\mathrm{j}}\right)$ :

(i) the price level falls beneath $\hat{\Pi}^{\circ}$ in period 2, but by less than the drop in the monev supply, and thereafter remains beneath $\hat{\pi}^{\circ}$ while rising asymptotically to $\hat{\pi}^{\prime \prime}$ :

(ii) the quantity transacted falls beneath $\hat{q}^{0}$ in period 2 , rises above $\hat{q}^{\prime \prime}$ in period 3 . 
and thereafter remains above $\hat{q}^{\circ}$ while falling asymptotically towards $\hat{q}^{\prime \prime}$.

\section{Concluding Remarks}

This paper presents a theory of price dynamics in which price adjustment depends on production lags. The theory rests on basic assumptions that are generally satisfied in modern market economies: current final goods are produced by means of past intermediate inputs, nominal wages depend on final output prices, and final ourpur prices are precommitted in advance of sales. Within this framework we have shown how changes in product demand - generated, say, by changes in the money supply - can have long-lasting price and quantity effects.

Specifically, permanent demand changes lead to "pricing sluggishness" and output responses during the adjustment process, and temporary demand changes lead to "pricing persistence". The degree of pricing sluggishness and persistence is tied to the productive structure of the economy (diminishing returns to factor inputs) and the elasticity of final product demand, rather than being exclusively associated with nominal rigidities, as in the menu cost and price staggering theories. Consequently our theory yields predictions about price-quantity dynamics that are observationally distinct from the prevailing theories of price inertia. 


\section{References}

Akerlof. George A. and Janet L. Yellen (1985). "A Near-Rational Model of the Business Cycle. with Wage and Price Inertia," Quarterly Journal of Economics, 100 (suppl). 823838.

Ball. Laurence, and Stephen Cecchetti (1988), "Imperfect Information and Staggered Price Setting." American Economic Review, 78, 999-1018.

Ball, Laurence, and David Romer (1989), "Are Prices Too Sticky?" Quarterly Journal of Economics, 104, 507-524.

Basu, Susanto (1995), "Intermediate Goods and Business Cycles: Implications For Productivity and Welfare," American Economic Review, 85(3), 512-531.

Blanchard, Olivier (1986), "The Wage-Price Spiral," Quarterly Journal of Economics. 101(3), 543-565.

Blinder, Alan S. (1981), "Inventories and the Structure of Macro Models," American Economic Review, Papers and Proceedings, 71(2), 11-16.

Carlton, Dennis W. (1986). "The Rigidity of Prices," American Economic Review, September. 76(4), 637-658.

Gordon, Robert J. (1990), "What is New-Keynesian Economics?" Joumal of Economic Literature, 28(3), 1115-1171.

Malinvaud. Edmond (1972), Lectures on Macroeconomic Theory, Amsterdam: North-Holland. Mankiw. N. Gregory (1985), "Small Menu Costs and Large Business Cycles: A Macroeconomic Model of Monopoly." Quarterly Journal of Economics, 100, 529-539.

Means, Gardiner C. (1935), "Industrial Prices and their Relative Inflexibility," U.S. Senate Document 13, 74th Congress, 1st Session, Washington, D.C.: U.S. Government Printing Office.

Phelps. Edmund S., and John B. Taylor (1977), "Stabilizing Powers of Monetary Policy with Rational Expectations," Journal of Political Economy, 85, 163-190.

Taylor, John B. (1979), "Aggregate Dynamics and Staggered Contracts," Journal of Political Economy, 88, 1-23. 
$\pi$ 45

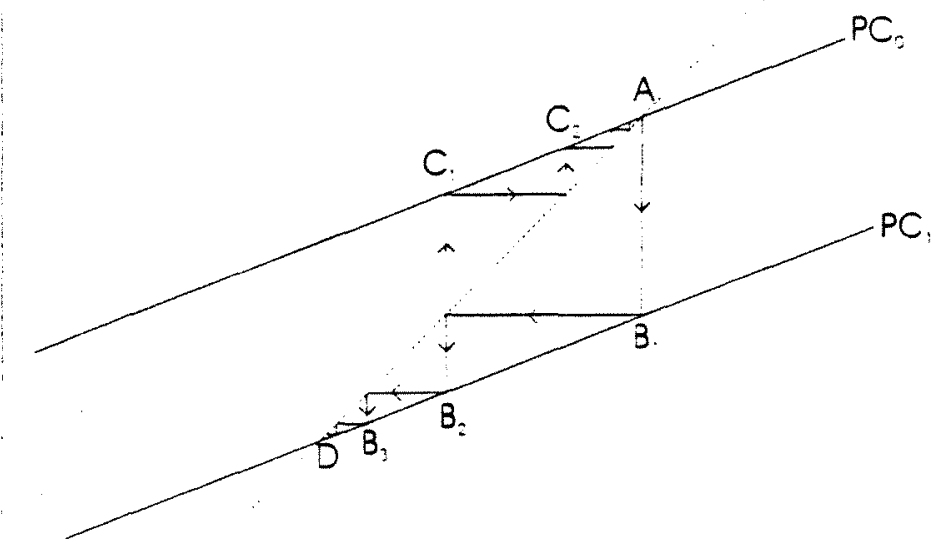

$\pi$

Figure 1: Price dynamics following a permanent and temporary demand shift 


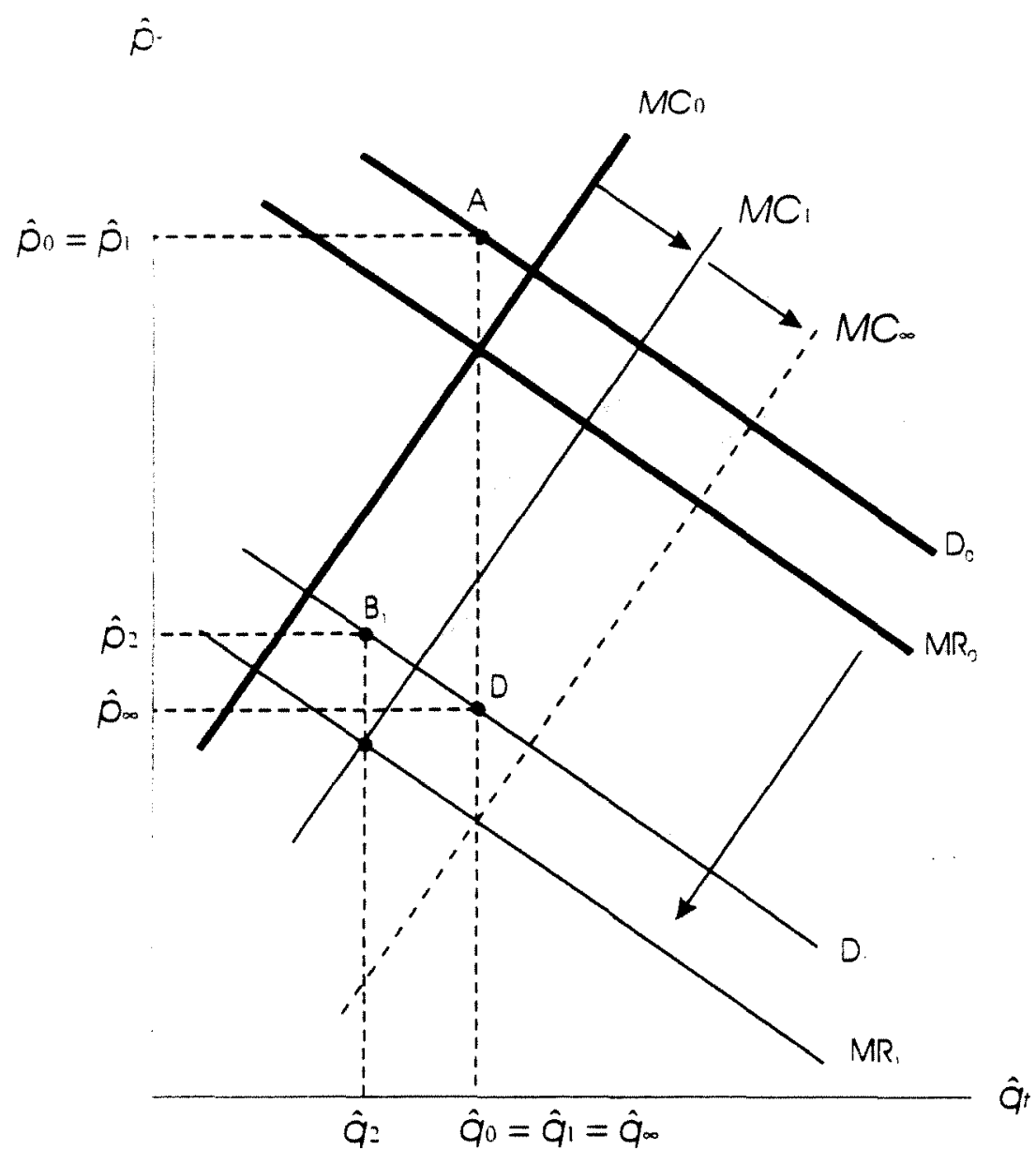

Figure 2a: Price-quantity decisions in response to a permanent demand shift 


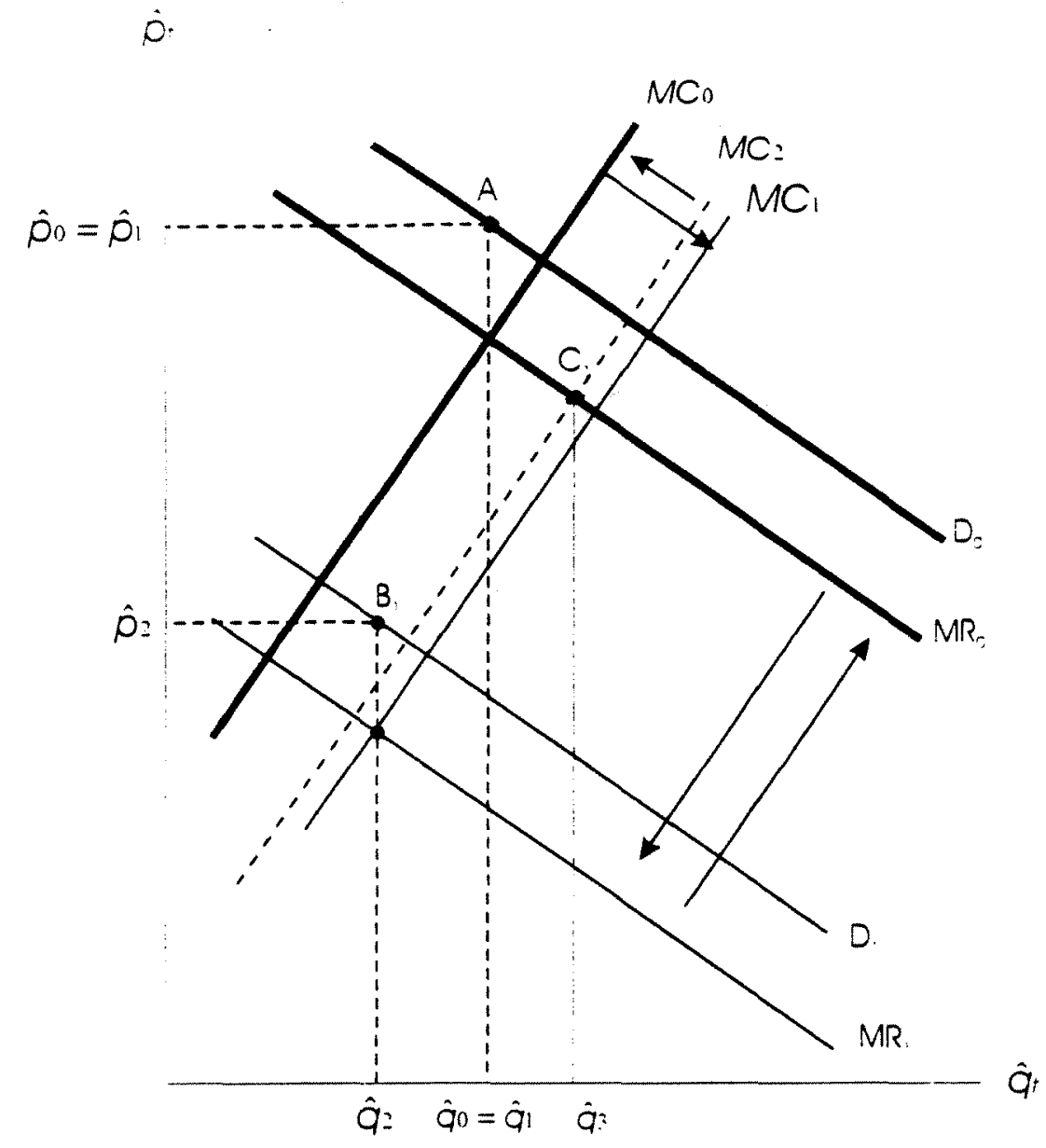

Figure 2b: Price-quantity decisions in response to a temporary demand shiff 


\section{APPENDLX}

\section{A1. The Dynamic Response to a Permanent Shock}

Figures 3 describe the sequence of price-quantity equilibria explicitly in terms of the interaction between the final good market and the intermediate good market. The market-clearing condition for the final good

$$
\hat{q}_{\mathrm{t}+1}=\gamma \hat{I}_{\mathrm{t}}=\hat{\alpha}+\varepsilon \cdot\left(\hat{M}-\hat{\Pi}_{\mathrm{t}+1}\right)
$$

is illustrated by the $Q E$ locus in Figure 3a. This locus is downward-loping in $\hat{I}_{t}-\hat{\Pi}_{t-1}$ space, since the supply of the final good $\hat{q}_{\mathrm{t}+1}$ depends positively on the intermediate input $\hat{I}_{\mathrm{t}}$ and the final demand depends negatively on the price level $\hat{\Pi}_{t+1}$.

The market-clearing condition for the intermediate good

$$
\hat{I}_{\tau}=\frac{\mu}{1-\mu \cdot \gamma} \cdot\left(\left(\hat{\Pi}_{t+1}-\hat{\Pi}_{t}\right)+(\hat{\delta}+\hat{e}+\hat{\gamma}+\hat{\mu} \cdot \hat{w})+(1-\gamma) \cdot \hat{F}+\left(\frac{1-\mu}{\mu}\right) \cdot \hat{\Phi}\right)
$$

is pictured by the IE locus. This locus is upward-sloping in $\hat{I}_{\mathrm{t}}-\hat{\Pi}_{\mathrm{t}+1}$ space, since an increase in the final good price level $\hat{\pi}_{t+1}$ (ceteris paribus) raises the demand for the intermediate good, $\hat{I}_{\mathrm{t}}^{\mathrm{d}}=\hat{F}+\frac{1}{1-\gamma} \cdot\left(\hat{\delta}+\hat{e}+\hat{\gamma}-\hat{P}_{\mathrm{t}}+\hat{\Pi}_{\mathrm{t}+1}\right)$, relative to the supply of the intermediate good, $\hat{l}_{\mathrm{t}}=\hat{\Phi}+\frac{\mu}{1-\mu} \cdot\left(\hat{\mu}-\hat{w}-\hat{\pi}_{\mathrm{t}}+\hat{P}_{\mathrm{t}}\right)$, at any given intermediate good price. thereby leading to a rise in the quantity (and price) of the intermediate good.

The initial equilibrium (at the beginning of period 0 ) is described by the intersection between the $Q E_{0}$ and $I E_{0}$ loci, point $A$ in Figure 3a. Now consider the effects of a permanent fall in the money supply, occurring in the course of period 0 and not anticipated until it occurs. This shock leaves the price-quantity combinations $p_{1}-q_{1}$ and $P_{0}-I_{0}$ unchanged, since these decisions were made at the beginning of period 0 . before the monetary shock was known. Thus market activity is pictured by points $A$ in Figures $3 \mathrm{a}-\mathrm{c}$, so that the intermediate good price-quantity combination in period 0 is $\left(\hat{P}_{0}, \hat{I}_{0}\right)$ and the final good price-quantity combination in period 1 is $\left(\hat{\pi}_{0}, \hat{q}_{0}\right)=\left(\hat{\pi}_{1}\right.$. $\left.q_{1}\right)$.

Now turn to the next round of price-quantity decisions: the period-1 decisions for the intermediate good $\left(\hat{P}_{1}, \hat{I}_{1}\right)$ and the period-2 decisions for the final goods $\left(\hat{\Pi}_{2}, \hat{q}_{2}\right)$. By equation (8), the permanent monetary shock causes the $Q E$ locus to shift downward to $Q E_{1}$ in period 1 and to remain there for all subsequent periods. By equation (11). the $I E$ locus in period 1 remains at its original position $\left(I E_{0}=I E_{1}\right.$ in Figure 3a), since the 
final good price is precommitted in period $1\left(\hat{\pi}_{1}=\hat{\pi}_{0}\right)$. The downward shift of the $Q E$ locus to $Q E_{1}$ along this unchanged $I E$ locus means that the general equilibrium moves from point $A$ to point $B_{1}$ in the Figure 3 a.

The underlying activity in the intermediate good market is pictured in Figure 3c. The precommitment of the final good price $\left(\hat{\Pi}_{1}=\hat{\Pi}_{0}\right)$ means that the nominal wage remains unchanged $\left(\hat{W}_{1}=\hat{W}_{0}\right)$. and consequently the intermediate good supply curve does not shift: $I_{0}^{s}=I_{1}^{s}$ in Figure $3 \mathrm{c}$. But the intermediate good demand curve drops to $I_{1}^{\mathrm{d}}$, in response to a drop in the final good price level (explained below). Thus the intermediate good price falls to $\hat{P}_{1}$ and the associated quantity falls to $\hat{I}_{1}$. Observe that even if the intermediate good demand curve were to fall proportionately to the monetary shock. the intermediate good price would fall less than proportionately to the final good price.

The final goods market is pictured in Figure $3 \mathrm{~b}$. Here the supply curve drops in response to the fall in the intermediate good price, while demand curve drops in response to the monetary shock. But since the intermediate good price falls less than proportionately to the monetary shock, the supply curve drops by less than the demand curve (i.e. the supply curve shifts only from $q_{1}^{\mathrm{s}}$ to $q_{2}^{\mathrm{s}}$, while the corresponding demand curve shifts from $q_{1}^{d}$ to $q_{1}^{d}$ ). Thus the final good price falls less than proportionately to the monetary shock (from $\hat{\Pi}_{1}$ to $\hat{\Pi}_{2}$ ) and final output falls (from $\hat{q}_{1}$ to $\hat{q}_{2}$ ). 1

In the following round of price-quantity decisions are the period-2 decisions for the intermediate good $\left(\hat{P}_{2}, \hat{I}_{2}\right)$ and the period-3 decisions for the final goods $\left(\hat{\Pi}_{3}, \hat{q}_{3}\right)$. By equation (11). the previous drop in the final good price level to $\hat{\Pi}_{2}$ leads to a drop in the $I E$ locus (from $I E_{1}$ to $I E_{2}$ in Figure 3a). As noted. the $Q E$ locus remains unchanged at $Q E_{1}$. The downward shift of the $I E$ locus along the $Q E_{1}$ locus makes the general equilibrium move to point $B_{2}$ in Figure $3 a$.

Figure $3 \mathrm{c}$ shows the corresponding changes in the intermediate good market. The fall in the final good price to $\hat{\Pi}_{2}$ leads to a proportional fall in the nominal wage to $\hat{W}_{2}$ (since the real wage remains constant). Thus the intermediate good supply curve shifts down to $I_{2}^{\mathrm{s}}$. Since the period-3 final good price falls by less (to $\Pi_{3}$ ), as explained below, the intermediate good demand curve shifts down to $I_{2}$. Thus the new equilibrium in the intermediate good market is characterized by a lower price (at $\hat{P}_{2}$ ) and a higher quantity (at $\hat{I}_{2}$ ).

The fall in the intermediate good price to $\hat{P}_{2}$ leads to an outward shift of the final good supply curve to $q_{3}^{5}$ in Figure $3 \mathrm{~b}$. Since the final good demand curve remains at $q_{1}^{d}$, the new equilibrium in the final good market fearures a lower price $\left(\right.$ at $\left.\hat{\pi}_{3}\right)$ and a

Fet since the final good price falls less than proportionately to the-monetary shock, the intermediate good demand curve must also shift less than proportionately. which makes the intermediate good price even more sluggish. 
higher quantity (at $\hat{q}_{3}$ ). The final good price $\hat{\Pi}_{3}$ falls by less than the intermediate good price $\hat{P}_{2}$, since the final good supply curve shifts along an unchange demand curve.

In this way. the final good price level gradually falls towards its now long-term equilibrium value $\hat{\Pi}_{\infty}$ and the outputs of the intermediate and final goods rise gradually towards their original levels.

Put differently the impact effect of the monetary shock is to shift each final good producer's marginal revenue curve downwards in proportion to the monetary shock. while the associated marginal cost curve shifts downwards by less (since the intermediate good price is sluggish). Thus the price and quantity of the final good both fall. Thereafter. the marginal revenue curve remains unchanged, while the marginal cost curve falls gradually (as the intermediate good price continues to fall). Consequently the price of the final good continues to fall. while the output gradually rises back to its original level.

\section{A2. The Dynamic Response to a Temporary Shock}

In terms of Figure 3a, the temporary monetary shock shifts the $Q E$ locus from $Q E_{0}$ to $Q E_{1}$ in period 1 and then back to $Q E_{0}$ thereafter. Since the final good price is precommitted in period 1 , the $I E$ locus remains at its original level in that period. Thus the general equilibrium point moves from point $A$ to point $B_{1}$ in period 2 . corresponding to a fall in the output and price of the final good. The reason is that since the final good price in period 1 is unchanged, the intermediate good price does not adjust fully to the shocks and thus the final good producers' marginal cost curve falls by less than the marginal revenue curve.

The drop in the period-2 final good price leads to a drop in the $I E$ locus from $I E_{1}$ to $I E_{2}$. That, together with the return of the $Q E$ locus to $Q E_{0}$ means that the general equilibrium moves from point $B_{1}$ to point $C_{1}$ in Figure $3 \mathrm{a}$, corresponding to a rise in the price and quantity of the final good in period 3. The reason is that since the final good price in period 2 fell, but less than proportionately to the temporary shock, the period-2 intermediate good price does so, too, and thus the final good producers' marginal cost curve falls while the marginal revenue curve remains at its previous level.

Along these lines, the price and quantity of the final good gradually rise to their original levels and the economy returns to point $A$ in Figure 3a. 


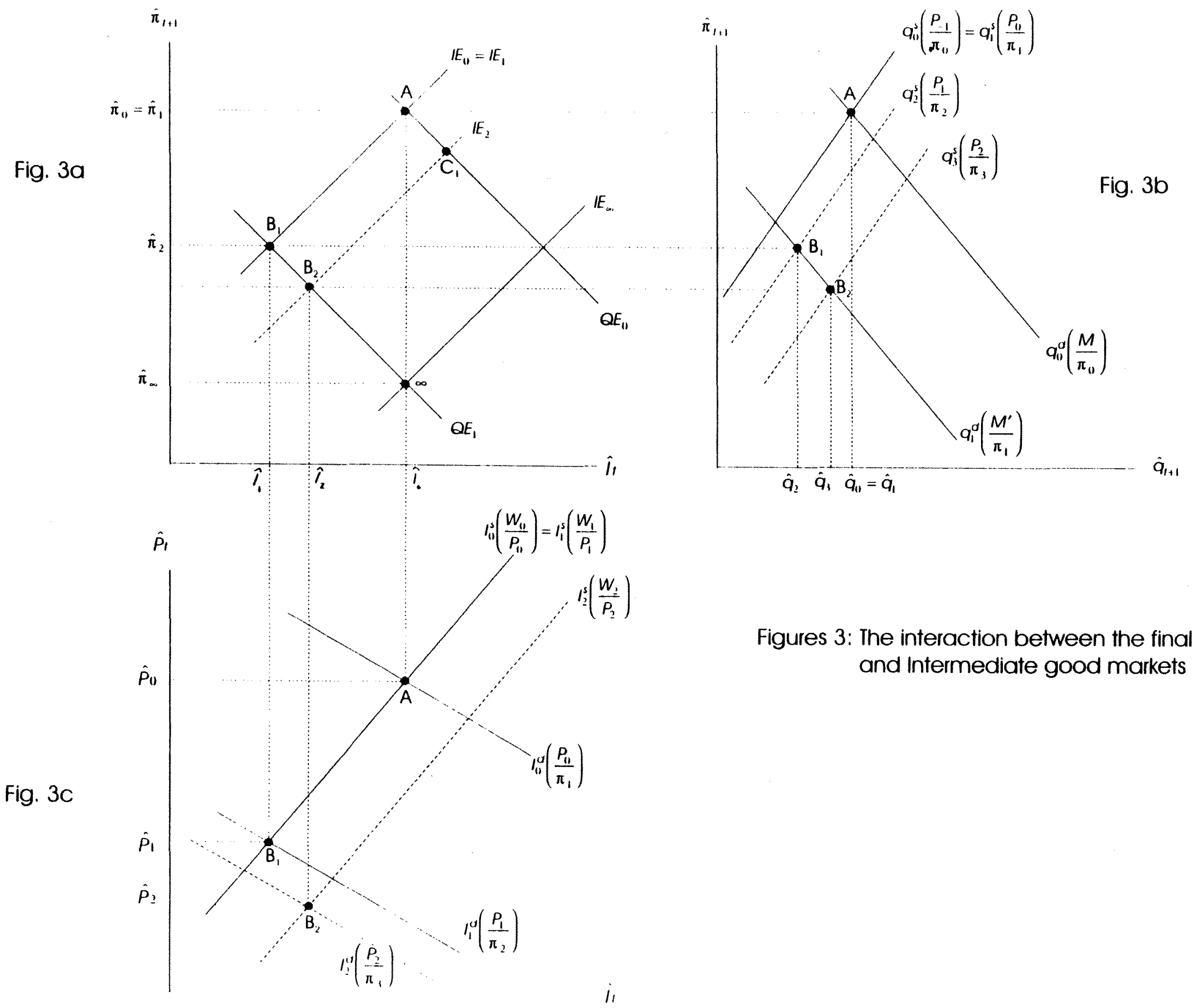

